\title{
Our Anesthetic Management for Brainstem Evoked a Response Audiometry in a Child with Ondine's Curse
}

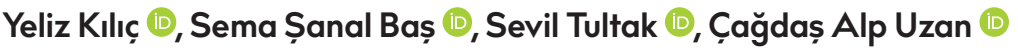 \\ Department of Anesthesiology and Reanimation, Eskișehir Osmangazi University School of Medicine, Eskișehir, Turkey
}

ORCID IDs of the authors: Y.K. 0000-0003-I446-7747; S.Ș.B. 0000-0002-2943-0456; S.T. 0000-0002-5022-266X; C..A.U. 0000-0003-24I2-7025.

Cite this article as: Kılıç Y, Șanal Baș S, Tultak S, Uzan ÇA. Our Anesthetic Management for Brainstem Evoked a Response Audiometry in a Child with Ondine's Curse. Cyprus J Med Sci 2018; 3(3): 204-5.

Dear Editor,

Congenital central hypoventilation syndrome (CCHS), also known as Ondine's curse, is a rare disease characterized by autonomic respiratory dysfunction without any pulmonary, cardiac, or neuromuscular disorder (I). This syndrome may be accompanied by seizures, gastroesophageal reflux disease (GERD), Hirschsprung's disease, and dysrhythmia (2). However, there are limited data on the anesthetic management of patients with CCHS (2-4).

A 2-year-old girl, $14 \mathrm{~kg}$ in weight, presented with hearing loss. Brain stem evoked audiometry (BERA) under general anesthesia was planned. The patient was diagnosed with $\mathrm{CCSH} 2$ months after the delivery due to apnea attacks and multiple seizures. She showed mild symptoms related to GERD. However, she had no history of respiratory distress, seizures, or gastrointestinal symptoms for the last I year and thus did not take any medication. Written informed consent was ontained from patient's parents.

Results of physical examination and routine laboratory tests were normal. Airway assessment was consistent with Mallampatti class I.

Monitoring included electrocardiography, noninvasive blood pressure measurement, and pulse oximetry. After preoxygenation, inhalation induction was performed with $8 \%$ sevoflurane in oxygen. Subsequently, anesthesia was induced with remifentanyl $(2 \mathrm{\mu g} / \mathrm{kg}$ ), lidocaine $(2.5 \mathrm{mg} / \mathrm{kg})$, and propofol $(4 \mathrm{mg} / \mathrm{kg})$, without a muscular relaxant. Laryngeal mask anaesthesia was performed using 2.5 size of mask. Anesthesia was maintained with (50\%/50\%) medical air/oxygen and $2 \%$ sevoflurane (via inhalation). The test lasted I h without any complication. She was closely followed up in the ward for $24 \mathrm{~h}$ and was uneventfully discharged the next day.

The main concern among anesthesiologists is the failure to control ventilation. Patients with CCHS are sensitive to central respiratory depressant effects of opioids, preoperative anesthetics, anxiolytics, inhalation agents, muscular relaxants, and benzodiazepines. Sevoflurane seems to be more suitable due to its rapid establishment of an anesthetic concentration and lack of airway irritation (5). CCHS is often accompanied by GERD, which is associated with increased risk of aspiration.

Central control of temperature may be problematic. Several preventions, such as increasing the room temperature and warming the respiratory gases and intravenous fluids, should be suggested (5).

Cardiovascular status should be taken into account in the maintenance of anesthesia. Anesthetic agents with short activity, such as sevoflurane, remifentanil, and nitrous oxide, may be suitable choices. Because seizures are common, anticonvulsant drugs should not be discontinued throughout the perioperative period. Additionally, the use of enflurane should be avoided because of its seizure-like effects (5).

In conclusion, anesthetists should be aware of this syndrome and associated disorders. Detailed preoperative evaluations along with appropriate medications and techniques are of great importance for successful anesthetic management.

This study was presented at the Turkish Society of Anaesthesiology and Reanimation 52. National Congress. 7-II November, 2018. Antalya, Turkey. 
Informed Consent: Written informed consent was ontained from patient's parents.

Peer-review: Externally peer-reviewed.

Author contributions: Concept - Y.K.; Design - Y.K.; Supervision - Y.K., S.Ș.B.; Resource - Y.K, S.Ș.B.; Materials - Y.K., S.T., C.A.U.; Data Collection and/or Processing - Y.K., S.T., C.A.U.; Analysis and/or Interpretation - Y.K., S.S..B.; Literature Search - Y.K., S.T., C..A.U.; Writing - Y.K.; Critical Reviews - Y.K., S.Ș.B., S.T., C.A.U.

Conflict of Interest: The authors have no conflicts of interest to declare.

Financial Disclosure: The authors declared that this study has received no financial support.

\section{REFERENCES}

I. Weese-Mayer DE, Berry-Kravis EM, Ceccherini I, Keens TG, Loghmanee DA, Trang H, et al. An official ATS clinical policy statement: Congenital central hypoventilation syndrome: genetic basis, diagnosis, and management. Am J Respir Crit Care Med 20I0; I8I: 626-44. [CrossRef]

2. Güçlü CCY, Bermede AO, Alanoğlu Z, Aybar S, Göllü G, Alkıș N Haddad Syndrome and Anesthesia: Case Report. Turkiye Klinikleri J Anest Reanim 2015; 13: 123-5. [CrossRef]

3. Niazi AU, Mocon A, Varadi RG, Chan VW, Okrainec A. Ondine's curse: anesthesia for laparoscopic implantation of a diaphragm pacing stimulation system. Can J Anaesth 20II; 58: 1034-8. [CrossRef]

4. Prottengeier J, Münster T, Wintermeyer P, Schmidt J. Anaesthesia for orphan disease: Haddad syndrome (Ondine-Hirschsprung disease). Eur J Anaesthesiol 2014; 31: 338-40. [CrossRef]

5. Strauser LM, Helikson MA, Tobias JD. Anesthetic care for the child with congenital central alveolar hypoventilation syndrome (Ondine's Curse). J Clin Anesth 1999; II: 431-7. [CrossRef] 